\title{
The Effect of Recombinant Granulocyte Colony-Stimulating Factor on Oral and Periodontal Manifestations in a Patient with Cyclic Neutropenia: A Case Report
}

\author{
Sergio Matarasso, Vincenzo Daniele, Vincenzo Iorio Siciliano, \\ Michele D. Mignogna, Gianmaria Andreuccetti, and Carlo Cafiero
}

Department of Odontostomatological and Maxillo-Facial Science, The School of Medicine and Surgery, Federico II University of Naples, Italy

Correspondence should be addressed to Carlo Cafiero, c.cafiero@unina.it

Received 4 May 2009; Revised 28 July 2009; Accepted 30 November 2009

Recommended by Jasim M. Albandar

Cyclic Neutropenia $(\mathrm{CN})$ is characterized by recurrent infections, fever, oral ulcerations, and severe periodontitis as result of the reduced host defences. The previous studies have established the effectiveness of recombinant granulocyte colony-stimulating factor (GCSF) to increase the number and the function of neutrophils in the peripheral blood in this disease. In a 20-year-old Caucasian female with a diagnosis of cyclic neutropenia, oral clinical examination revealed multiple painful ulcerations of the oral mucosa, poor oral hygiene conditions, marginal gingivitis, and moderate periodontitis. The patient received a treatment with G-CSF (Pegfilgrastim, $6 \mathrm{mg} / \mathrm{month}$ ) in order to improve her immunological status. Once a month nonsurgical periodontal treatment was carefully performed when absolute neutrophil count (ANC) was $\geq 500 / \mu \mathrm{L}$. The treatment with G-CSF resulted in a rapid increase of circulating neutrophils that, despite its short duration, leaded to a reduction in infection related events and the resolution of the multiple oral ulcerations. The disappearance of oral pain allowed an efficacy nonsurgical treatment and a normal tooth brushing that determined a reduction of probing depth $(\mathrm{PD} \leq 4 \mathrm{~mm})$ and an improvement of the oral hygiene conditions recorded at 6-month follow-up.

Copyright (C) 2009 Sergio Matarasso et al. This is an open access article distributed under the Creative Commons Attribution License, which permits unrestricted use, distribution, and reproduction in any medium, provided the original work is properly cited.

\section{Introduction}

Neutrophils play a critical role in the host defence mechanism against bacterial infections [1]. There are 3 general guidelines used to classify the severity of neutropenia based on the absolute neutrophil count (ANC) measured in cells per microliter of blood:

(i) mild neutropenia $(1000 \leq$ ANC $<1500)$-minimal risk of infection,

(ii) moderate neutropenia $(500 \leq$ ANC $<1000)$ moderate risk of infection,

(iii) severe neutropenia (ANC < 500)—severe risk of infection.

The above mentioned ranges were developed in Caucasians. In colored population, mild neutropenia is a normal phenomenon, and neutropenia in this population is more properly defined as ANC < 1200. Higher cutoffs may lead to overdiagnosis of neutropenia in the colored population [2]. The clinical consequence of the disease is an increased infective diathesis proportional to the severity of the neutropenia. Several forms of neutropenia (agranulocytosis, familiar benign neutropenia, severe chronic neutropenia) can be found associated with oral manifestations. Severe chronic neutropenia is characterized by a selective decrease in circulating neutrophils and includes a heterogeneous group of haematological diseases divided into three main syndromes: idiopathic neutropenia, congenital forms of neutropenia, and cyclic neutropenia.

The present paper is aimed at evaluating the efficacy of a non surgical periodontal treatment associated with G-CSF therapy in a patient suffering from cyclic neutropenia $(\mathrm{CN})$ 


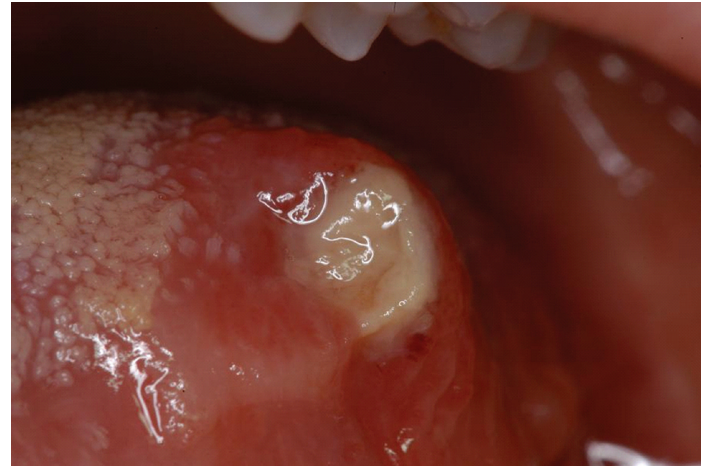

FIGURE 1: Ulceration of tongue.

associated with oral manifestations and periodontal disease. Written informed consent was obtained by the patient and the authors declare no conflict of interest related to this paper.

\section{Case Presentation}

A 20-year-old Caucasian female with diagnosis of $\mathrm{CN}$ was referred by the Department of Immunology and Allergology, to the Department of Periodontology of the University of Naples Federico II, Italy. Anamnesis revealed that since the first year of life the patient has been suffering from repeated phases of fever and oral ulcerations, associated with pain and lymphadenopathy. During childhood and adolescence the patient had repeated admissions to the hospital, but $\mathrm{CN}$ was diagnosed only in September 2007. The haematological findings (complete laboratory work-up) showed the neutropenic phase recurred approximately every 21 days. The lowest neutrophil count was $0,20 \times 10^{3} / \mu \mathrm{L}$. A light enlargement of submandibular and cervical lymph nodes was revealed by palpation and moreover fever $\left(37,8^{\circ} \mathrm{C}\right)$ sinusitis and pharyngitis were recorded during the neutropenic phase. In addition she reported to brush her teeth three times a day but during the neutropenic crisis oral hygiene was hindered by pain due to oropharyngeal ulcerations (Figures 1, 2, and 3). Full Mouth Plaque Score (FMPS) and Full Mouth Bleeding Score (FMBS), recorded on 6 sites per tooth, were $66.7 \%$ and $64.8 \%$, respectively (Figure 4 ). Periodontal examination revealed a generalized increased probing depths (Figure 5). No furcations were involved and no gingival recessions were recorded. Tooth mobility was not present. An X-ray examination revealed bone loss on interproximal aspect of maxillary and mandibular teeth (Figure 6). A diagnosis of moderate periodontitis as manifestation of systemic disease was made.

Since September 2007 up till February 2008 the patient received a systemic treatment with Prednisolone $10 \mathrm{mg} /$ die o.s./7 days (Deltacortene, Bruno Farmaceutici) during the neutropenia phases. The above therapy had a minimum effect on severity of oral ulcerations and produced minimal improvement in ANC. At this regard pain and burning determined poor oral hygiene conditions (FMPS = $41.3 \%$ and FMBS $=4.2 \%$ ).

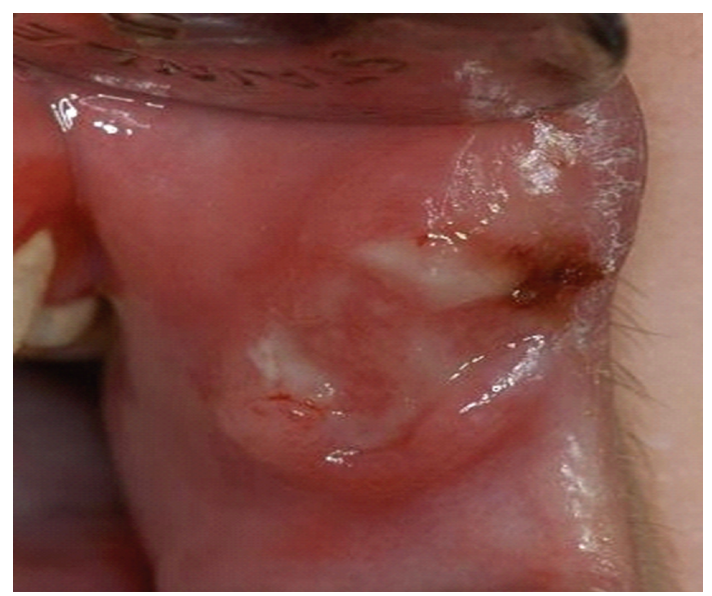

FIgURE 2: Ulceration of labial commissural.

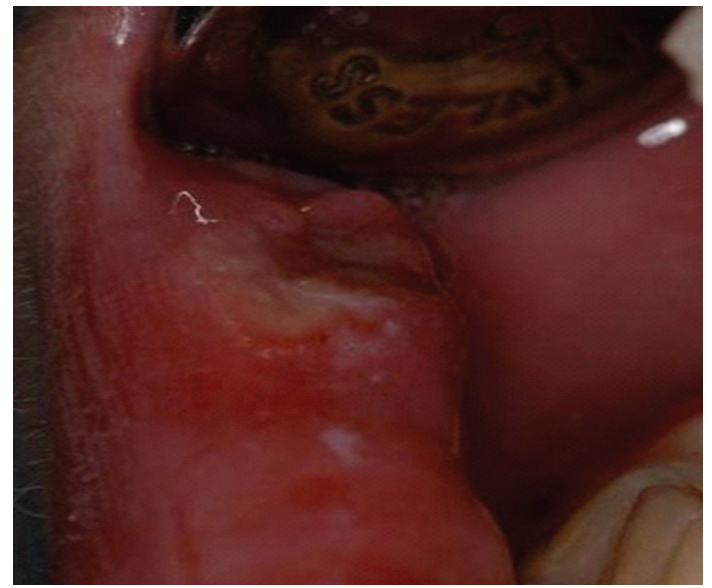

FIGURE 3: Ulceration of lower lip.

In March 2008, the patient received a new treatment with GCSF administration consisting of subcutaneous injection of Pegfilgrastim $6 \mathrm{mg}$ (Neupopeg, Dompè Biotec S.p.A., Italy) once a month.

Periodontal treatment including oral hygiene instructions, scaling, root planning, and polishing was meticulously carried out once a month when absolute neutrophil count (ANC) was $>1500 / \mu \mathrm{L}$ and for this reason prophylactic antibiotic therapy was not prescribed. During neutropenic cycles the patient was advised to rinse her mouth twice a day with $0.2 \%$ chlorhexidine gluconate. A very high level of compliance was recorded. A complete laboratory workup was performed every week. Therapy with G-CSF initially led to a "peak" of WBC and ANC and subsequently to a normalization for few days (Table 1). No side effects has been reported by the patient during the treatment and no adverse effects were noted when the counts were greater than $40 \times 10^{3} / \mu \mathrm{L}$. A reduction of general and oral manifestations during the neutropenic cycles was constantly recorded. One week after neutropenic phase periodontal re-evaluation was carried out in order to assess the plaque control and the tissutal response to the treatment. 


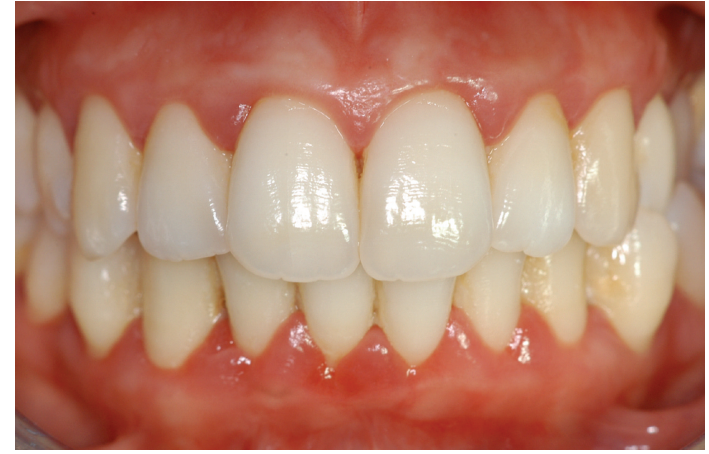

FIgURE 4: Frontal view of clinical situation at baseline.

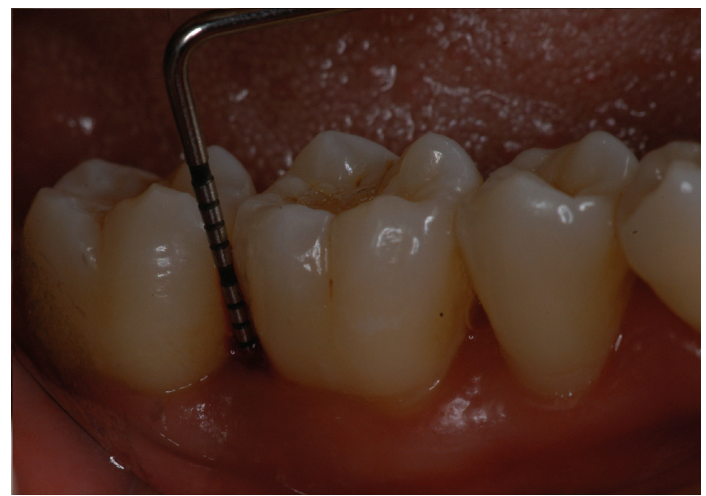

Figure 5: Pathological probing depths were recorded at baseline.

A considerable improvement of oral hygiene conditions was observed: FMPS and FMBS remained constantly $\leq 25 \%$ and a period general reduction of probing depth (PD $\leq 4 \mathrm{~mm}$ ) during the successive 6-month follow-up was recorded (Figures 7 and 8). Microbiological analysis was performed. Microbiological sampling included selection of the deepest periodontal pocket in each quadrant of the dentition based on the probing depth measurements. Sample sites were isolated with cotton rolls and supragingival plaque was carefully removed with curettes and cotton pallets. Subsequently, two paper points were inserted to the depth of the pocket and left in place for 10 seconds.

The paper points were transferred to a vial to be send to the microbiological laboratory in order to perform Polymerase Chain Reaction (PCR, Lab Oral International, The Netherlands). Microbiological analysis revealed no residual pathogenic subgingival microflora but an elevated level of Fusobacterium nucleatum.

\section{Discussion}

Cyclic neutropenia $(\mathrm{CN})$ is a chronic rare disorder in the production of the neutrophils, presenting at about 19-21 days intervals. It is clinically characterized by a periodic decrease in the circulating neutrophil numbers determining recurrent infections.

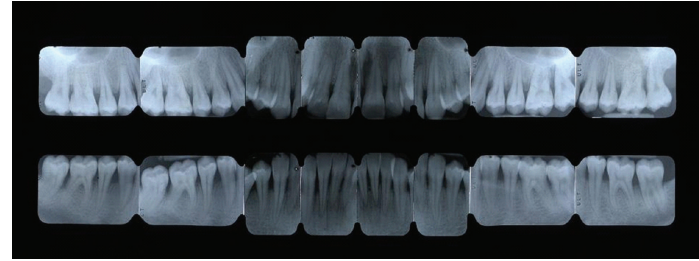

Figure 6: X-ray examination at baseline.

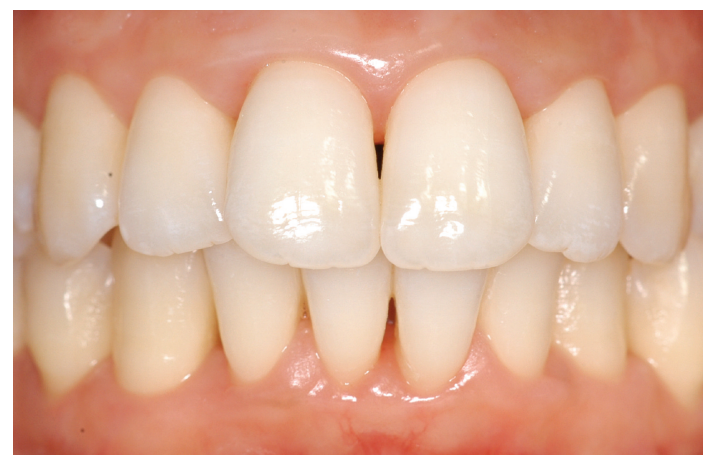

Figure 7: Frontal view of clinical situation after 12-month followup period.

$\mathrm{CN}$ is transmitted by autosomal dominant gene and occurs in infancy but occasionally in adult life [3]. $\mathrm{CN}$ is identified as an intrinsic defect of granulocyopoiesis, whose molecular alteration resides in the gene of neutrophil elastase (ELA 2) located on the chromosome 19p13.3.

In the early maturation stage, the mutation of the gene ELA2 led to an intramedullary apoptosis of neutrophils, that causes regular phases of neutropenia in peripheral blood [4]. The neutropenic phases are typically reported to fall in the range of 19 to 21 days, although recent data indicate that longer periods occur in some patients. The episodes last 5-8 days [5]. The diagnostic criterion of $\mathrm{CN}$ is absolute neutrophil count (ANC) less than $0.5 \times 10^{3} / \mu \mathrm{L}$, at least 3 to 5 consecutive days per cycle, for each of three regularly spaced cycles.

As a result of neutropenic phases, haematological findings could reveal increasing in the number of platelets, monocytes, lymphocytes, eosinophils, and reticulocytes [6]. Neutropenia predisposes to respiratory or muco-cutaneous bacterial infection and in some cases was reported in association with otitis media and upper respiratory infection [7]. These manifestations are similar, but less severe, to those commonly reported by patients suffering from agranulocytosis. A general malaise, fever, lymphadenopathy, and oral ulcerations are very common findings during neutropenic periods [8]. Severe periodontitis and oral ulcerations have been reported in the majority of the recorded cases, meanwhile ulcerations may be the unique oral manifestation in about $20 \%$ of patients [9-11]. The mucosal lesions can affect any part of the oral mucosa during the neutropenic phases and cause pain and very intense burning that could discourage the patient to maintain a good oral hygiene. 
TABle 1: Haematological examinations during G-CSF therapy (March-September 2008).

\begin{tabular}{|c|c|c|c|c|}
\hline Date & $\begin{array}{c}\text { WBC } \\
\left(10^{3} / \mu \mathrm{L}\right)\end{array}$ & $\begin{array}{l}\text { NEUTR } \\
\left(10^{3} / \mu \mathrm{L}\right)\end{array}$ & $\begin{array}{c}\text { LIMPH } \\
\left(10^{3} / \mu \mathrm{L}\right)\end{array}$ & $\begin{array}{l}\text { MONO } \\
\left(10^{3} / \mu \mathrm{L}\right)\end{array}$ \\
\hline $17 / 03 / 2008$ & 4.87 & 1.93 & 2.5 & 0.19 \\
\hline $24 / 03 / 2008$ & 3.13 & 0.86 & 1.66 & 0.35 \\
\hline $31 / 03 / 2008$ & 2.53 & 0.15 & 1.44 & 0.74 \\
\hline $05 / 04 / 2008$ & 3.35 & 0.42 & 1.78 & 0.86 \\
\hline $20 / 04 / 2008$ & 2.8 & 0.04 & 1.71 & 0.92 \\
\hline $21 / 04 / 2008$ & \multicolumn{3}{|c|}{ Subcutaneous injection of G-CSF } & \\
\hline $28 / 04 / 2008$ & 49.5 & 43.56 & 4.16 & 1.29 \\
\hline $06 / 05 / 2008$ & 6.44 & 3.12 & 2.76 & 0.32 \\
\hline $10 / 05 / 2008$ & 4 & 1.48 & 2.04 & 0.36 \\
\hline $13 / 05 / 2008$ & 3 & 0.83 & 1.66 & 0.39 \\
\hline $17 / 05 / 2008$ & 2.1 & 0.05 & 1.51 & 0.38 \\
\hline $24 / 05 / 2008$ & 2.4 & 0.33 & 1.29 & 0.68 \\
\hline $29 / 05 / 2008$ & 3.43 & 0.53 & 1.96 & 0.66 \\
\hline $30 / 05 / 2008$ & \multicolumn{3}{|c|}{ Subcutaneous injection of G-CSF } & \\
\hline $31 / 05 / 2008$ & 4.12 & 1.03 & 2.51 & 0.37 \\
\hline 04/06/2008 & 6.4 & 0.48 & 2.49 & 3.17 \\
\hline 08/06/2008 & 48.93 & 41.39 & 4.06 & 2.15 \\
\hline $11 / 06 / 2008$ & 21.13 & 16.48 & 3.4 & 0.76 \\
\hline $15 / 06 / 2008$ & 4.3 & 2.18 & 1.78 & 0.21 \\
\hline $18 / 06 / 2008$ & 3.4 & 1.52 & 1.54 & 0.22 \\
\hline $22 / 06 / 2008$ & 4.06 & 1.49 & 1.8 & 0.52 \\
\hline $27 / 06 / 2008$ & 3.2 & 0.39 & 1.77 & 0.97 \\
\hline $28 / 06 / 2008$ & \multicolumn{3}{|c|}{ Subcutaneous injection of G-CSF } & \\
\hline $29 / 06 / 2008$ & 3.67 & 0.38 & 1.82 & 1.01 \\
\hline $02 / 07 / 2008$ & 21.57 & 16.22 & 3.28 & 1.27 \\
\hline 06/07/2008 & 19.48 & 13.56 & 4.36 & 0.64 \\
\hline 09/07/2008 & 19.41 & 14.4 & 3.98 & 0.58 \\
\hline $13 / 07 / 2008$ & 4.4 & 2.17 & 1.78 & 0.34 \\
\hline $18 / 07 / 2008$ & 3.1 & 1.32 & 1.64 & 0.2 \\
\hline $22 / 07 / 2008$ & 4.16 & 1.48 & 1.7 & 0.51 \\
\hline $27 / 07 / 2008$ & 3.1 & 0.34 & 1.6 & 0.99 \\
\hline $28 / 07 / 2008$ & \multicolumn{3}{|c|}{ Subcutaneous injection of G-CSF } & \\
\hline $29 / 07 / 2008$ & 3.68 & 0.33 & 1.8 & 1.09 \\
\hline $02 / 08 / 2008$ & 22.47 & 17.21 & 3.18 & 1 \\
\hline 06/08/2008 & 18.47 & 14.54 & 4.26 & 0.54 \\
\hline 09/08/2008 & 18.41 & 14.43 & 3.68 & 0.52 \\
\hline $13 / 08 / 2008$ & 4.4 & 2.27 & 1.88 & 0.54 \\
\hline $17 / 08 / 2008$ & 2.8 & 0.07 & 1.5 & 0.35 \\
\hline $24 / 08 / 2008$ & 2.7 & 0.35 & 1.25 & 0.65 \\
\hline 29/08/2008 & 3.45 & 0.53 & 1.88 & 0.77 \\
\hline 30/08/2008 & \multicolumn{3}{|c|}{ Subcutaneous injection of G-CSF } & \\
\hline $31 / 08 / 2008$ & 5.12 & 1.33 & 2.59 & 0.39 \\
\hline $41 / 91 / 2008$ & 6.3 & 0.48 & 2.47 & 3.47 \\
\hline 08/09/2008 & 48.93 & 41.42 & 4.06 & 2.26 \\
\hline $11 / 09 / 2008$ & 22.43 & 16.18 & 3.5 & 0.77 \\
\hline $15 / 09 / 2008$ & 4.33 & 2.28 & 1.79 & 0.22 \\
\hline
\end{tabular}

WBC: White blood cell count; Neutr: Neutrophil; Limph: Lymphocytes; Mono: Monocytes. 


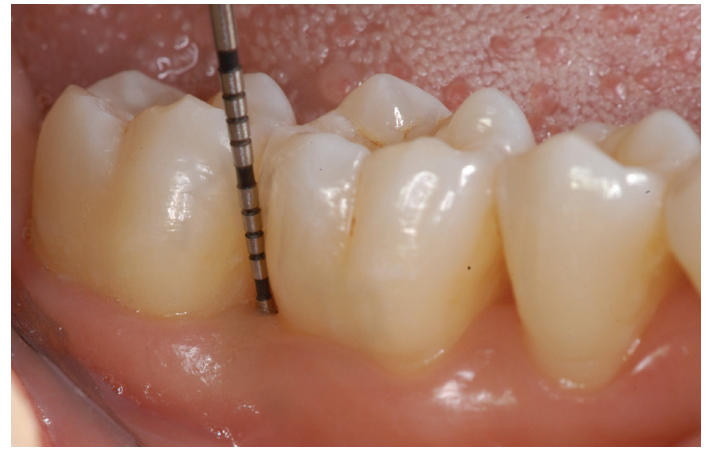

Figure 8: After 12-month follow-up period the periodontal probing show a PD of $3 \mathrm{~mm}$.

Gingivitis is common in $\mathrm{CN}$ and severe periodontitis may affect both deciduous and permanent dentitions [12]. In the international literature, severe periodontitis is constantly recorded in subject suffering from $\mathrm{CN}$ [13-16], meanwhile this case report is characterized by few periodontal lesions demonstrating that a significant decrease of neutrophil polymorphonucleate leukocytes could be associated with moderate periodontal lesions. Medical management of neutropenias is mainly symptomatic and consists of aggressive antibiotic treatment of febrile patients suspected of having bacterial infections. Other therapies of uncertain efficacy include glucocorticoids, androgenic steroids, immunoglobulins, and plasmapheresis [17-21]. In the last years therapeutic protocols based on the use of recombinant granulocyte colony-stimulating factor (G-CSF) [22-25] that increases for few days the number and the function of neutrophils in the peripheral blood have been proposed by several authors [2629]. Filgrastim is a granulocyte colony-stimulating factor (GCSF) analog used to stimulate the proliferation and differentiation of granulocytes. It is produced by recombinant DNA technology and is only slightly different from G-CSF naturally made in humans. Pegfilgrastim is a pegylated form of Filgrastim: pegylation leads to prolongation of its half-life without loss of activity $[22,23]$. The recent data demonstrate that Pegfilgrastim, at doses ranging from 6 to $12 \mathrm{mg}$ alone or together with chemotherapy, is capable of efficiently mobilizing peripheral blood stem cells, thus resulting in rapid reconstitution of haematopoiesis. According to data present in the literature, in which no clinically meaningful difference between a single monthly dose of Pegfilgrastim $(6 \mathrm{mg})$ and multiple daily doses of Filgrastim $(5 \mu \mathrm{g} / \mathrm{kg} / \mathrm{die})$ was recorded, a single dose of G-CSF (Pegfilgrastim) was monthly administered to the patient [30-33], but there are no organized trials to test or compare Pegfilgrastim versus Filgrastim or other types of G-CSF for treatment of cyclic or chronic neutropenia.

The monthly therapy with G-CSF caused a rapid increase of circulating neutrophils that, even if of short duration, determined the disappearance of oral ulcerations during the neutropenic phases. These results confirm the outcomes found in the literature, in which the use of G-CSF determined a reduction of oral ulcerations in patient suffering from CN [20]. Moreover the disappearance of ulcerations determined an enhancement of the compliance of the patient who meticulously followed the oral care program.

At 6-month follow-up nonsurgical treatment of the periodontitis determined a general reduction of probing depth (PD $\leq 4 \mathrm{~mm}$ ) and a proper tooth brushing leads to an improvement of oral hygiene resulting in an effective plaque control by the patient (FMPS $\leq 25 \%$; FMBS $\leq 25 \%$ ). At baseline the patient refused to undergo to microbiological analysis and accepted at 6-month follow-up. At 6-month follow-up microbiological analysis revealed no residual pathogenic subgingival microflora but an elevated level of Fusobacterium nucleatum.

Fusobacterium nucleatum is an anaerobic Gram-negative nonsporeforming oral bacterium found in the normal flora of the mouth, that plays a role in periodontal disease. Because of its opportunistic nature, Fusobacterium nucleatum does not affect the environment directly and is not considered a major dental pathogen on its own although it can adhere to a wide range of other organisms, such as Porphyromonas gingivalis, and contribute to the development of periodontitis. On the basis of the present microbiological results, a systemic antibiotic therapy was not prescribed to the patient. In conclusion the present results showed that the therapy with recombinant granulocyte colony-stimulating factor (G-CSF) allowed the oral mucosa to heal and influenced the entity of neutropenic cycle. Moreover the periodontal treatment is effective in a patient with $\mathrm{CN}$ when compliance is sufficient high to follow the maintenance care program.

\section{Acknowledgments}

The authors thank Professor Massimo Triggiani and Professor Angela Petraroli, Department of Immunology and Allergology of the University of Naples Federico II, for the medical management of the present case.

\section{References}

[1] A. W. Segal, "How neutrophils kill microbes," Annual Review of Immunology, vol. 23, pp. 197-223, 2005.

[2] M. M. Hsieh, J. E. Everhart, D. D. Byrd-Holt, J. F. Tisdale, and G. P. Rodgers, "Prevalence of neutropenia in the U.S. population: age, sex, smoking status, and ethnic differences," Annals of Internal Medicine, vol. 146, no. 7, pp. 486-492, 2007.

[3] Y. Nakai, C. Ishihara, S. Ogata, and T. Shimono, "Oral manifestations of cyclic neutropenia in a Japanese child: case report with a 5-year follow-up," Pediatric Dentistry, vol. 25, no. 4, pp. 383-388, 2003.

[4] C. Bellanné-Chantelot, S. Clauin, T. Leblanc, et al., "Mutations in the ELA2 gene correlate with more severe expression of neutropenia: a study of 81 patients from the French Neutropenia Register," Blood, vol. 103, no. 11, pp. 4119-4125, 2004.

[5] C. Haurie, D. C. Dale, and M. C. Mackey, "Cyclical neutropenia and other periodic hematological disorders: a review of mechanisms and mathematical models," Blood, vol. 92, no. 8, pp. 2629-2640, 1998.

[6] M. C. Dinauer, J. A. Lekstrom-Himes, and D. C. Dale, "Inherited neutrophil disorders: molecular basis and new therapies," Hematology, pp. 303-318, 2000. 
[7] J. F. Prichard, D. M. Ferguson, J. Windmiller, and W. C. Hurt, "Prepubertal periodontitis affecting the deciduous and permanent dentition in a patient with cyclic neutropenia. A case report and discussion," Journal of Periodontology, vol. 55, no. 2, pp. 114-122, 1984.

[8] C. Scully, E. MacFadyen, and A. Campbell, "Oral manifestations in cyclic neutropenia," British Journal of Oral Surgery, vol. 20, no. 2, pp. 96-101, 1982.

[9] L. M. Long Jr., J. R. Jacoway, and J. W. Bawden, "Cyclic neutropenia: case report of two siblings," Pediatric Dentistry, vol. 5, no. 2, pp. 142-144, 1983.

[10] P. Spencer and J. E. Fleming, "Cyclic neutropenia: a literature review and report of case," ASDC Journal of Dentistry for Children, vol. 52, no. 2, pp. 108-113, 1985.

[11] N. Yamalik, E. Yavuzyilmaz, F. Cağlayan, et al., "Periodical gingival bleeding as a presenting symptom of periodontitis due to underlying cyclic neutropenia. Case report," Australian Dental Journal, vol. 38, no. 4, pp. 272-276, 1993.

[12] H. Rylander and I. Ericsson, "Manifestations and treatment of periodontal disease in a patient suffering from cyclic neutropenia," Journal of Clinical Periodontology, vol. 8, no. 2, pp. 77-87, 1981.

[13] I. Brodsky, H. A. Reimann, and L. H. Dennis, "Treatment of cyclic neutropenia with testosterone," The American Journal of Medicine, vol. 38, no. 5, pp. 802-806, 1965.

[14] D. G. Wright, A. S. Fauci, D. C. Dale, and S. M. Wolff, "Correction of human cyclic neutropenia with prednisolone," The New England Journal of Medicine, vol. 298, no. 6, pp. 295300, 1978.

[15] K. J. Roozendaal, K. A. Dicke, and M. L. B. Flaes, "Effect of oxymetholone on human cyclic haematopoiesis," British Journal of Haematology, vol. 47, no. 2, pp. 185-193, 1981.

[16] D. S. Verma, G. Spitzer, A. R. Zander, K. A. Dicke, and K. B. McCredie, "Cyclic neutropenia and T lymphocyte suppression of granulopoiesis: abrogation of the neutropenic cycles by lithium carbonate," Leukemia Research, vol. 6, no. 4, pp. 567576, 1982.

[17] G. K. Von Schulthess, J. Fehr, and C. Dahinden, "Cyclic neutropenia: amplification of granulocyte oscillations by lithium and long-term suppression of cycling by plasmapheresis," Blood, vol. 62, no. 2, pp. 320-326, 1983.

[18] B. I. Lord, L. B. Woolford, and G. Molineux, "Kinetics of neutrophil production in normal and neutropenic animals during the response to filgrastim (r-metHu G-CSF) or filgrastim SD/01 (PEG-r-metHu G-CSF)," Clinical Cancer Research, vol. 7, no. 7, pp. 2085-2090, 2001.

[19] G. Molineux, "The design and development of pegfilgrastim (PEG-rmetHuG-CSF, Neulasta)," Current Pharmaceutical Design, vol. 10, no. 11, pp. 1235-1244, 2004.

[20] D. C. Dale, M. A. Bonilla, M. W. Davis, et al., "A randomized controlled phase III trial of recombinant human granulocyte colony-stimulating factor (filgrastim) for treatment of severe chronic neutropenia," Blood, vol. 81, no. 10, pp. 2496-2502, 1993.

[21] G. Simon and L. Maródi, "Successful treatment of cyclic neutropenia associated with hyperimmunoglobulin $\mathrm{M}$ syndrome using recombinant granulocyte-colony stimulating factor," Orvosi Hetilap, vol. 136, no. 40, pp. 2169-2172, 1995.

[22] W. Bensinger, J. Singer, F. Appelbaum, et al., "Autologous transplantation with peripheral blood mononuclear cells collected after administration of recombinant granulocyte stimulating factor," Blood, vol. 81, no. 11, pp. 3158-3163, 1993.
[23] S. Kitagawa, A. Yuo, L. M. Souza, M. Saito, Y. Miura, and F. Takaku, "Recombinant human granulocyte colonystimulating factor enhances superoxide release in human granulocytes stimulated by the chemotactic peptide," Biochemical and Biophysical Research Communications, vol. 144, no. 3, pp. 1143-1146, 1987.

[24] A. Yuo, S. Kitagawa, A. Ohsaka, et al., "Recombinant human granulocyte colony-stimulating factor as an activator of human granulocytes: potentiation of responses triggered by receptor-mediated agonists an stimulation of C3bi receptor expression and adherence," Blood, vol. 74, no. 6, pp. 21442149, 1989.

[25] R. Repp, T. Valerius, A. Sendler, et al., "Neutrophils express the high affinity receptor for $\operatorname{IgG}(\mathrm{Fc} \gamma \mathrm{RI}, \mathrm{CD} 64)$ after in vivo application of recombinant human granulocyte colonystimulating factor," Blood, vol. 78, no. 4, pp. 885-889, 1991.

[26] P. Holmstrup and M. Glick, "Treatment of periodontal disease in the immunodeficient patient," Periodontology 2000, vol. 28, no. 1, pp. 190-205, 2002.

[27] P. N. Baer and V. J. Iacono, "Cyclic neutropenia: report of a case with a 15-year follow up," Periodontal Clinical Investigations, vol. 16, no. 1, pp. 14-19, 1994.

[28] R. J. Genco, "Current view of risk factors for periodontal diseases," Journal of Periodontology, vol. 67, supplement 10, pp. 1041-1049, 1996.

[29] M. A. da Fonseca and F. Fontes, "Early tooth loss due to cyclic neutropenia: long-term follow-up of one patient," Special Care in Dentistry, vol. 20, no. 5, pp. 187-190, 2000.

[30] F. A. Holmes, S. E. Jones, J. O'Shaughnessy, et al., "Comparable efficacy and safety profiles of once-per-cycle pegfilgrastim and daily injection filgrastim in chemotherapy-induced neutropenia: a multicenter dose-finding study in women with breast cancer," Annals of Oncology, vol. 13, no. 6, pp. 903-909, 2002.

[31] M. D. Green, H. Koelbl, J. Baselga, et al., "A randomized double-blind multicenter phase III study of fixed-dose singleadministration pegfilgrastim versus daily filgrastim in patients receiving myelosuppressive chemotherapy," Annals of Oncology, vol. 14, no. 1, pp. 29-35, 2003.

[32] J. Sierra, J. Szer, J. Kassis, et al., "A single dose of pegfilgrastim compared with daily filgrastim for supporting neutrophil recovery in patients treated for low-to-intermediate risk acute myeloid leukemia: results from a randomized, double-blind, phase 2 trial," BMC Cancer, vol. 8, article 195, 2008.

[33] N. Russell, R. Mesters, J. Schubert, et al., "A phase 2 pilot study of pegfilgrastim and filgrastim for mobilizing peripheral blood progenitor cells in patients with non-Hodgkin's lymphoma receiving chemotherapy," Haematologica, vol. 93, no. 3, pp. 405-412, 2008. 


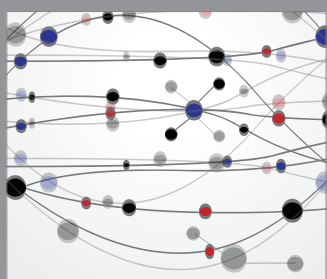

The Scientific World Journal
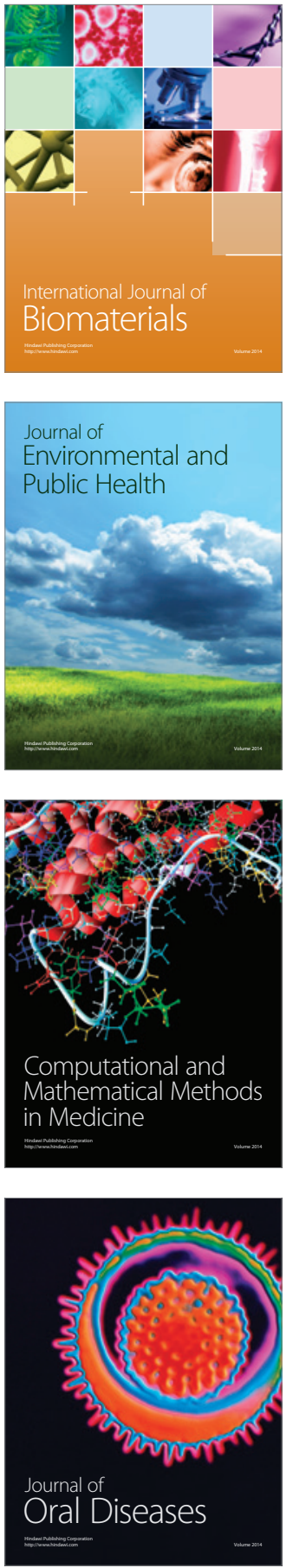
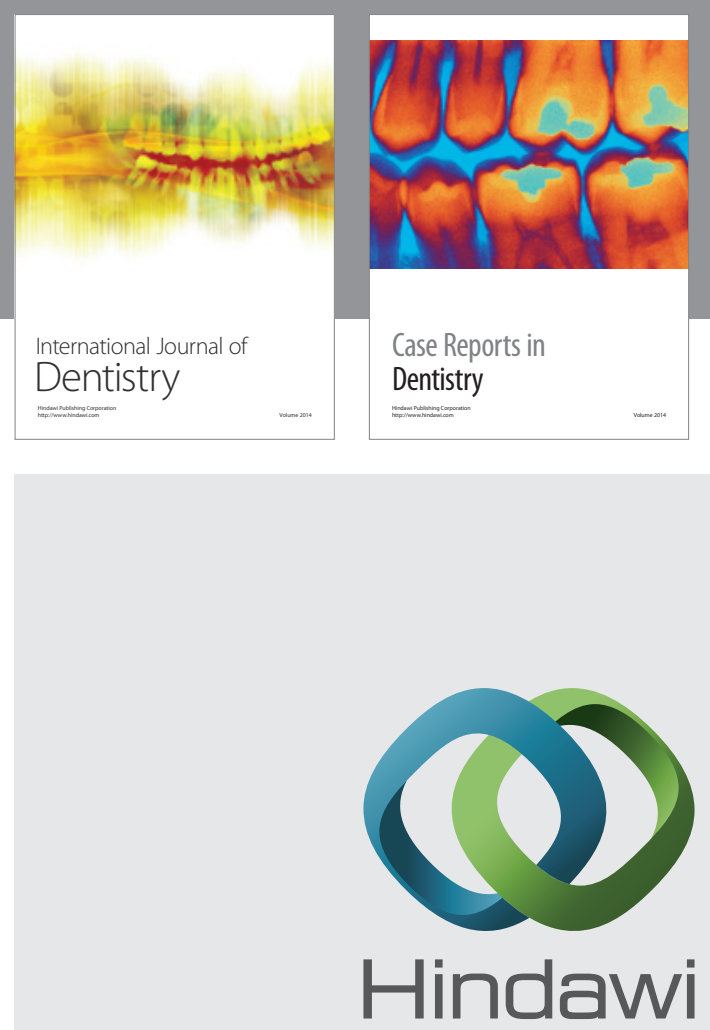

Submit your manuscripts at

http://www.hindawi.com
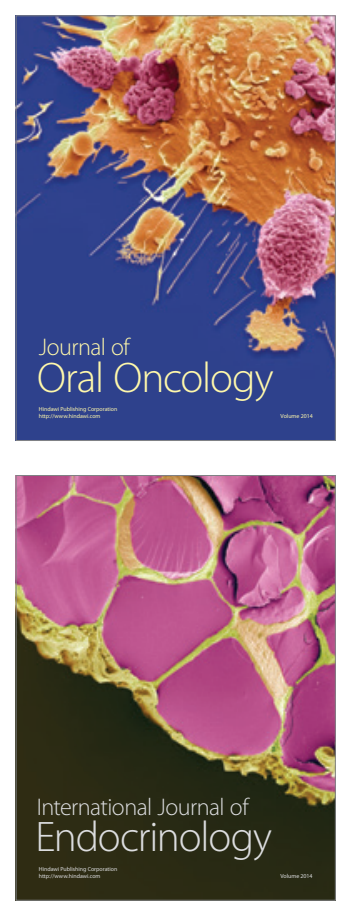
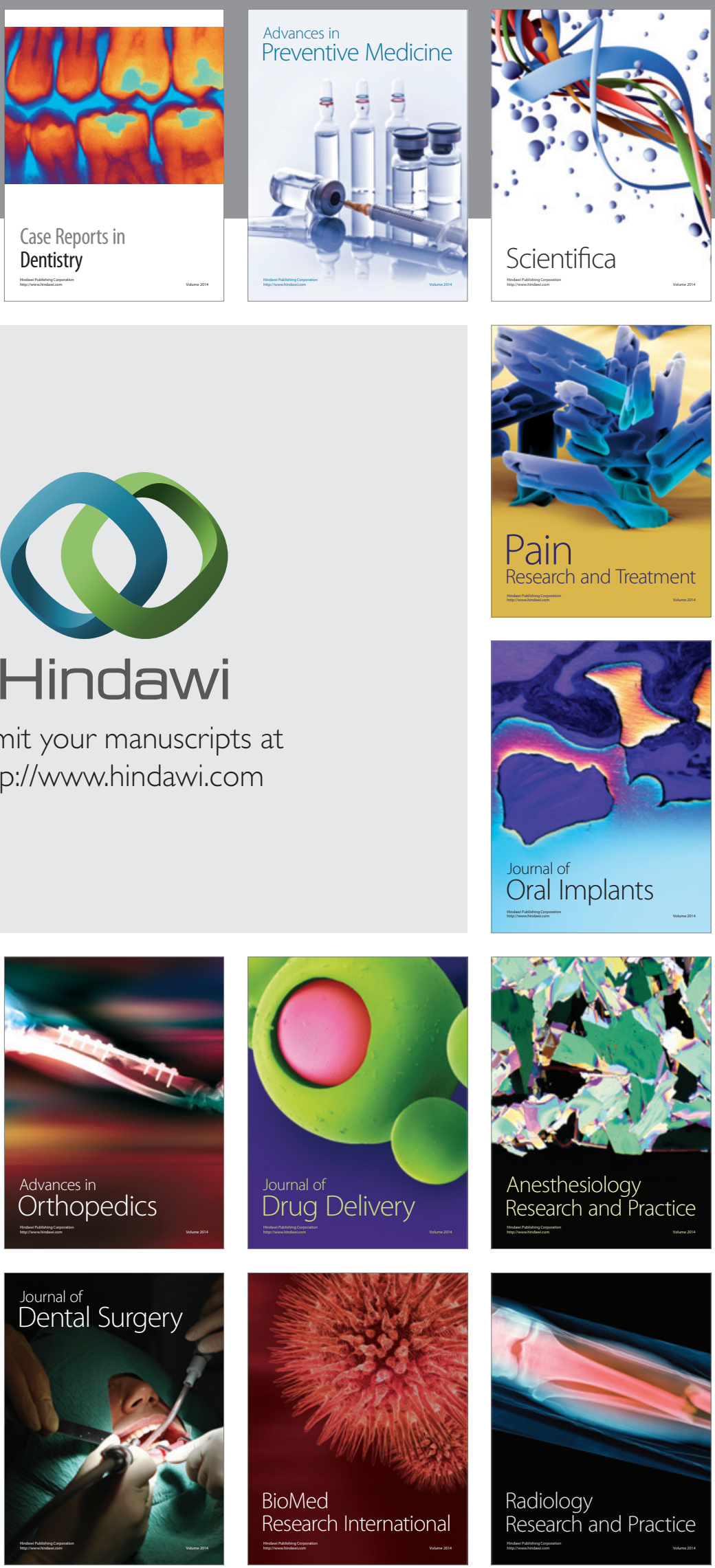